\author{
ЗМІНА ПАРАДИГМИ МОДЕЛЮВАННЯ ТА ПРОГНОЗУВАННЯ \\ СОЦІАЛЬНО-ЕКОНОМІЧНИХ СИСТЕМ \\ CHANGING THE PARADIGM OF MODELING AND FORECASTING \\ SOCIO-ECONOMIC SYSTEMS
}

УДК 330.46

https://doi.org/10.32843/bses.64-26

\section{Коломієць С.В.}

к.ф.-м.н., доцент,

доцент кафредри економічної

кібернетики

Сумський державний університет

Дініц P.O.

студент

Сумський державний університет

Kolomiiets Svitlana

Sumy State University

Dinits Ruslan

Sumy State University

\begin{abstract}
Сучасні наддинамічні та нелінійні умови фрункціонування економіки потребують зміни парадигми моделювання та прогнозування соціально-економічних систем. Реальні соціально-економічні, технічні та біологічні системи демонструють спільні есректи: циклічний розвиток, кризи, хаос, зародження нових станів, що дає змогу застосовувати методи нелінійної динаміки, які були розроблені в природничих науках, для вивчення складних соціально-економічних систем. Як математичні моделі соціально-економічних систем найчастіше використовуються системи дифреренціальних рівнянь, які відображають нелінійні зв'язки між елементами систем. Дослідження відповідних систем дифреренціальних рівнянь дає змогу аналізувати безліч потенційних шляхів розвитку соціально-економічної системи та вибирати найбільш раціональний шлях. у статmі досліджується актуальне питання зміни парадигми моделювання та прогнозування соціально-економічних систем. Теоретично обірунтовано необхідність переходу від лінійної до нелінійної парадигми в економічних дослідженнях, розглянуто особливості застосування методів нелінійної динаміки до моделювання соціально-економічних систем, розкрито феномен нелінійності соціально-економічних систем.

Ключові слова: сочіально-економічна система, нелінійність розвитку, динамічні моделі.
\end{abstract}

Современные сверхдинамические и нелинейные условия фрункционирования эко- номики требуют изменения парадигмы моделирования и прогнозирования социально-экономических систем. Реальные социально-экономические, технические и биологические системы демонстрируют общие эфрфекты: чиклическое развитие, кризисы, хаос, зарождение новых состояний, что позволяет применять методы нелинейной динамики, которые были разработаны в естественных науках, для изучения сложных социально-экономических систем. В качестве математических моделей социально-экономических систем чаще всего используются системы дисрференциальных уравнений, которые отражают нелинейные связи междуэлементами систем. Исследование соответствующих систем дифрференциальных уравнений позволяет анализировать множество потенциальных путей развития социально-экономической системы и выбирать наиболее рациональный путь. В статье исследуется актуальный вопрос смены парадигмы моделирования и прогнозирования социально-экономических систем. Теоретически обоснована необходимость перехода от линейной к нелинейной парадигме в экономических исследованиях, рассмотрены особенности применения методов нелинейной динамики к моделированию социально-экономических систем, изучен феномен нелинейности социально-экономических систем.

Ключевые слова: социально-экономическая система, нелинейность развития, динамические модели.

Modern socio-economic systems demonstrate instability, chaos, and unpredictability. What methodology should be used to modeling modern socio-economic systems? Constant changes and crises in the development of socio-economic systems require new approaches to the research of these systems. The feature of the approach to the study of socio-economic systems in modern conditions is the conversion from a linear to a nonlinear paradigm. The models of socio-economic systems are systems of nonlinear differential equations. Nonlinear differential equations demonstrate different modes of functioning of complex socio-economic systems. Nonlinear equations can have several qualitatively different solutions. This explains the existence of different ways of evolution of nonlinear socio-economic systems. Nonlinearity is a fundamental position of new paradigm of cognition and development. Nonlinearity is a general law of nature and means, first of all, non-observance of the principle of superposition. The whole cannot be the sum of its parts; the result cannot be the sum of efforts, the quality of the whole is not determined by the sum of the qualities of its parts, the reaction of the system is not proportional to the influence. For nonlinear phenomena, knowledge about the behavior of a part of an object does not yet guarantee correct ideas about the behavior of the object as a whole, and its response to changes in conditions may qualitatively depend on the magnitude of these changes. Non-linearity is the multivariance of the evolutionary paths, the presence of a choice of alternative paths and determining the rate of evolution. Nonlinearity is the irreversibility of evolutionary processes; nonlinear, indirect dependence of evolutionary processes on external influences. The article examines the topical issue of changing the paradigm of modeling and forecasting socio-economic systems. The necessity of transition from linear to nonlinear paradigm in economic research is theoretically substantiated. The features of the application of methods of nonlinear dynamics to the modeling of socio-economic systems are considered. The phenomenon of nonlinearity of socio-economic systems is studied. Key words: socio-economic system, nonlinearity of development, dynamic models.

Постановка проблеми. Сучасний світ демонструє непрогнозовану поведінку складних соціально-економічних систем та їх непередбачувані властивості. За вказаних умов виникає необхід- ність використання та розроблення нових підходів до моделювання та дослідження соціально-економічних систем, що базуються на іншій парадигмі парадигмі нелінійності. Початок XXI ст. позначився 
посиленням уваги до нелінійних процесів та механізмів самоорганізації у соціально-економічних системах. Найбільш затребуваними методами дослідження складних соціально-економічних систем $€$ методи нелінійної динаміки, пов'язані 3 пошуком єдиних механізмів розвитку нелінійних систем будь-якої природи - від фрізичних і біологічних до економічних і соціальних. Використання методів нелінійної динаміки для побудови адекватних моделей соціально-економічних систем та прогнозування економічної динаміки $€$ актуальними завданнями сьогодення.

Аналіз останніх досліджень і публікацій. Сучасні міждисциплінарні дослідження складних систем будь-якої природи демонструють принципову відмінність законів, що визначають поведінку цих систем, від законів класичної науки. Об'єкти дослідження класичної наукової парадигми - стійкість, рівновага, порядок, замкнені системи, лінійні залежності. У рамках класичного підходу економічні процеси розглядалися як зворотні за часом, які можна передбачити на необмежені проміжки часу. Класичний підхід не враховував вплив випадкових фракторів, розглядав випадковість як другорядний чинник.

Лінійні залежності та рівноважні стани, які $€$ характерними для неокласичної економічної теорії, не є адекватними для моделювання та прогнозування поведінки сучасних складних соціально-економічних систем. Сучасна парадигма моделювання та прогнозування поведінки соціально-економічних систем - це парадигма нелінійності.

Нелінійність є об'єктивним загальним законом розвитку складних систем будь-якої природи, що означає, перш за все, відсутність принципу суперпозиції:

- неможливість зведення фрункціонування всієї системи до фрункціонування їі елементів, ціла система не є просто сумою частин системи, вона якісно інша через установлення загального темпу розвитку частин систем;

- непропорційне співвідношення між причинами та наслідками, між величиною впливу та реакцією системи на цей вплив.

У сучасній економічній науці актуальними $\epsilon$ питання щодо можливостей економічного прогнозування та адекватного моделювання складних соціально-економічних систем, передбачення сценаріїв розвитку таких систем.

Аналіз наукових публікацій [1-14] засвідчив, що особливістю багатьох економічних процесів $\epsilon$ нелінійність, унаслідок чого вказані процеси та відповідні динамічні моделі можуть мати кілька станів рівноваги, як стійких, так і нестійких. За вказаних умов моделювання та дослідження поведінки складних соціально-економічних систем повинно базуватися на методах нелінійної динаміки.
Лінійне моделювання не дає змоги адекватно дослідити поведінку соціально-економічної системи в умовах порушення стійкості стаціонарного стану, в умовах динамічних змін. Дослідження нестаціонарних станів системи має спиратися саме на нелінійне моделювання.

Питанням моделювання соціально-економічних систем методами нелінійної динаміки присвячено роботи С. Демберела, В.-Б. Занга, Е. Петерса, Т. Пу, Д.С. Чернавського, В.В. Лебедєва, М.Ю. Малкова, В.П. Милованова, Л.Ф. Петрова, В.І. Маєвського, Д.І. Трубецького, Г.Г. Малинецького, А.Б. Потапова, В.В. Вітлінського, В.Д. Дербенцева, Ю.В. Коляди, Т.С. Клєбанової, В.М. Соловйова, О.І. Черняка та багатьох інших науковців.

Аналіз досліджень, присвячених питанням економічної динаміки, демонструє посилення уваги науковців до застосування методів нелінійної динаміки до моделювання соціально-економічних систем. Проте проблема моделювання поведінки соціально-економічних систем, проблема переходу до нової парадигми дослідження соціальноекономічних систем настільки складні та різноманітні, що потребують подальших досліджень у цій сорері. Це й зумовило вибір теми дослідження.

Постановка завдання. Метою статті $€$ теоретичне обґрунтування необхідності переходу до нелінійної парадигми в економічних дослідженнях, розкриття особливостей нелінійного підходу до моделювання динаміки соціально-економічних систем.

Виклад основного матеріалу дослідження. Глобалізація, становлення інноваційного типу економіки, значна конкуренція, проникнення Інтернет-технологій у всі соціально-економічні сорери, зростання обсягів інфрормації, ускладнення бізнес-процесів - усі ці чинники вимагають зміни парадигми моделювання соціально-економічних систем, яка повинна базуватися на сучасних фрундаментальних наукових дослідженнях.

Наприкінці XX ст. відбулася зміна наукової парадигми. Класична наукова картина абсолютизувала поступовий та поступальний розвиток, який зумовлений причинно-наслідковими зв'язками, що не залежать від незначних випадкових впливів на систему. Реакція системи вважалася обов'язково пропорційною впливу. Процеси навколишнього світу розглядалися як передбачувані на необмежено великі проміжки часу. Уважалося, що сьогодення визначається лише минулим, а майбутнє теперішнім та минулим.

Усі дослідження і висновки класичної науки базувалися на стереотипах лінійного мислення:

- розуміння хаосу виключно як деструктивного явища;

- розглядання випадковості як другорядного чинника, який не має принципового значення у розвитку; 
- розуміння нестійкості та не рівноважних станів виключно як негативних та руйнівних чинників;

- розуміння процесів оточуючого світу та суспільства як процесів, зворотних за часом, які можуть бути передбачуваними на необмежені проміжки часу;

- уявлення про жорсткі причинно-наслідкові зв'язки між процесами та явищами;

- розуміння розвитку лише як лінійного та поступального;

- розуміння зовнішнього впливу як однозначного та лінійного, що передбачає отримання бажаного результату лише за умови зовнішнього впливу: вплив - бажаний результат.

Додатковим підґрунтям для застосування лінійних стереотипів мислення до дослідження систем різної природи був досконалий лінійний математичний апарат, який розглядався як частина математичної культури.

Сучасний світ виявився хаотичним, катастрофрічним, непередбачуваним. За таких умов однозначна детермінованість $€$ лише частковим випадком, а передбачуваність - принципово обмеженою. Реальні системи, як правило, відкриті та нелінійні. Замкненість та лінійність - виняток із правил, спрощення дійсності.

На думку С.Ю. Малкова [1], дотепер для аналізу та прогнозування соціально-економічних процесів використовується економетричний метод, який базується на виявленні тенденцій розвитку за допомогою статистичної обробки різних економічних показників. В умовах стабільного розвитку цей підхід є цілком адекватним. Але в сучасних наддинамічних та нелінійних умовах фрункціонування соціально-економічних систем потрібне використання іншого наукового інструментарію, зокрема методів нелінійної динаміки та економічної синергетики. Методи нелінійної динаміки мають на меті дослідження нерівноважних процесів, виявлення закономірностей утворення нових соціально-економічних структур за руйнування попередніх.

Як зазначено у [2], проблема пошуку стійких і безпечних траєкторій розвитку соціально-економічних систем має безпосереднє відношення до нелінійної динаміки. Соціально-економічні системи - це складні ієрархічні системи, ступінь нестійкості та межі передбачуваності яких - різні. У сучасних умовах горизонт прогнозування розвитку соціально-економічних систем значно скоротився, водночас сталий розвиток суспільства вимагає повільно мінливих стратегічних цілей, суспільних цінностей, норм, культури та ідеології. Усе це вимагає використання відповідної теорії та методів, які б давали змогу аналізувати можливу динаміку систем, швидкість розвитку яких різна, та, базуючись на цих висновках, передбачати та направляти розвиток указаних систем. Указані завдання можуть бути розв'язані в рамках вико- ристання методів нелінійної динаміки, метою якої $€$ вивчення законів розвитку та еволюції нелінійних систем найрізноманітнішої природи.

На думку науковців [3], нелінійна динаміка це єдиний методологічний підхід, який дає змогу на основі об'єктивних законів досліджувати розвиток найрізноманітніших динамічних систем різної складності - від механічних до соціальноекономічних. Саме застосування методів нелінійної динаміки для аналізу поведінки складних соціально-економічних систем надає можливість зрозуміти механізми еволюції та механізми виникнення кризових явищ у таких системах. Ефекти нелінійної динаміки можуть бути використані для підвищення економічної ефективності, стійкості розвитку соціально-економічних систем, а також як інструменти антикризового управління.

На переконання дослідників [4], XX ст. та початок XXI ст. можна розглядати як століття панування лінійних законів, на яких будувалися прогнози та моделі фрункціонування ринків, підприємств і організацій, характерних для пануючої в економічній теорії неокласичної економічної думки. Головний постулат лінійної теорії економічних систем - прагнення економічних систем до рівноваги, тобто все у світі та в економічній сорері прагне до рівноваги: рівноважна ціна, рівновага попиту і пропозиції тощо. Згідно з лінійною теорією, реакція системи на влив $€$ пропорційною величині цього впливу. Окрім того, ринок «не має пам'яті», окрема подія не може його змінити, реакція економічної системи на зовнішній вплив завершується за умови завершення дії зовнішнього впливу. У рамках лінійної парадигми динаміка розвитку ринків та підприємств, поведінка споживачів описувалася лінійними залежностями. Нині все більше вчених підтримують думку щодо абстрактності лінійного підходу, його нездатності наблизитися до реальної економічної дійсності, ігнорування нової економічної реальності, яка не вписується в лінійну парадигму дослідження складних систем.

Як зазначається у [5], сучасне століття - це «століття нелінійності». Саме прогрес у розвитку науки дав змогу перейти від лінійної парадигми до нелінійної. Лінійні функції одного чи багатьох аргументів достатньо одноманітні: про властивості багатьох лінійних функцій можна робити висновок, досконало вивчивши одну 3 таких функцій. Властивості фрункцій залишаються також за збільшення кількості незалежних змінних: однаковим приростам незалежної змінної відповідають однакові прирости залежної змінної. Лінійні залежності, які є придатними для моделювання рівномірного зростання або рівномірного спадання, не $є$ придатними для моделювання резонансних явищ, насичення, коливань. Хоча прикладів лінійності безліч, глобальні процеси та явища не відповідають вимогам лінійної схеми. 
Як підкреслюється у [6, с. 51], світова економічна криза 2008 р., окрім складних економічних проблем, продемонструвала, перш за все, неможливість прогнозування таких криз у рамках лінійної парадигми. Дослідження поведінки соціальноекономічних систем на основі нелінійної динаміки дають змогу будувати моделі з урахуванням передкризових та кризових явищ. Зокрема, передкризові явища характеризуються ускладненням динаміч ного процесу: наближенням до точок біфуркації, появою складних полігармонічних розв'язків; для кризових явищ характерними є якісні зміни в поведінці системи: втрата стійкості, біфуркації, перехід до динамічного хаосу в детермінованих системах.

Ми повністю поділяємо думку науковців, що сучасна економіка характеризується наявністю нестабільних, нерівноважних, нестаціонарних процесів, які відбуваються в умовах невизначеності, соціально-економічні системи відрізняються значною мінливістю поведінки, різноманіттям зв'язків між елементами систем, що не дає змогу адекватно досліджувати сучасні економічні системи та процеси, базуючись лише на принципах лінійної парадигми.

У сучасних умовах постійних змін та криз необхідне глибоке осмислення нелінійної динаміки економічних процесів. Нелінійність, незворотність економічних процесів, сумісне фрункціонування швидких та повільних складників економіки пояснюють існування широкого спектру шляхів можливого економічного розвитку. Прогнозувати особливості поведінки траєкторій економічної еволюції можна на основі математичного та комп'ютерного моделювання.

Аналіз наукових публікацій засвідчив, що для моделювання та прогнозування розвитку соціально-економічних систем доцільно застосовувати методи нелінійної динаміки, що були розроблені в природничих науках. Для простих механічних систем існують доступні для дослідження моделі на основі нелінійних дисреренціальних рівнянь, які повністю відображають динаміку процесу з урахуванням складних нелінійних ефектів. При цьому нелінійні ефекти: втрата динамічної стійкості, біфуркація розв'язків системи, перехід до хаосу, дивний аттрактор підтверджуються експериментально.

Для моделювання поведінки складних соціально-економічних систем поряд із математичними методами значне місце займає комп'ютерне моделювання. Як математичні моделі найчастіше використовуються системи дисреренціальних рівнянь, які відображають нелінійні зв'язки між елементами систем. Нелінійні системи диференціальних рівнянь порівняно 3 лінійними системами демонструють різні режими фрункціонування складних соціально-економічних процесів, оскільки навіть незначна зміна параметрів неліній- ної системи може призвести до різкої зміни динаміки системи.

Оскільки загальних методів отримання аналітичного розв'язку систем нелінійних диференціальних рівнянь не існує, а використання сучасних програмних продуктів дає змогу знайти лише частинний розв'язок для конкретних значень параметрів, важливу роль відіграють методи якісного дослідження систем дифреренціальних рівнянь. Дослідження та прогнозування різних режимів поведінки нелінійної моделі соціально-економічної системи можуть базуватися на вивченні фразового портрету системи - сукупності всіх її можливих траєкторій, побудованих у просторі фразових змінних. Аналіз фразового портрету системи дає змогу передбачити всю сукупність режимів, які можуть виникнути за певних значень параметрів. Зокрема, серед траєкторій є ті, що визначають якісні властивості системи: точки рівноваги, які відповідають стаціонарним режимам системи, граничні цикли, що відповідають режимам періодичних коливань, тощо.

Реальні соціально-економічні системи, технічні та біологічні системи демонструють спільні ефректи: циклічний розвиток, кризи, хаос, зародження нових станів, що дає змогу застосовувати моделі, розроблені для технічних та біологічних систем для дослідження та прогнозування складних соціально-економічних систем.

Принципова відмінність моделей механіки від економічних моделей полягає у тому, що функціональні залежності та величина коефіцієнтів для моделей механіки повністю визначаються постановкою завдання, водночас для побудови аналогічних моделей економіки необхідні додаткові дослідження для визначення параметрів моделей. Саме через невирішеність проблем визначення функціональних залежностей та коефіцієнтів рівнянь математичний апарат теорії нелінійних коливань, синергетики, теорії катастроф достатньо складно використовувати для кількісного аналізу економічної динаміки [7].

Один із методів визначення фрункціональних залежностей та коефіцієнтів у моделях нелінійної економічної динаміки запропоновано у [7]. Основний апарат дослідження - чисельні методи, під час застосування яких неважливими є конкретний вигляд функціональної залежності та величина коефріцієнтів. Форма залежності, величини коефіцієнтів визначаються за статистичними даними. Якщо така залежність наближається до відомої залежності, то завдання значно спрощується. Якщо ж реальні залежності не можуть бути апроксимовані відомими функціями, то можуть бути використані сплайни, що дає змогу застосувати методи моделювання, які використовуються в теорії нелінійних коливань, теорії катастроф до задач нелінійної економічної динаміки. 
Виділимо основні ефекти нелінійної динаміки, які необхідно обов'язково враховувати під час дослідження та прогнозування соціально-економічних систем [3]:

- відсутність принципу суперпозиції: нелінійна система не є простою сумою окремих складників;

- можливість існування кількох стійких станів;

- коливання, що властиві соціально-економічним системам, мають складний, комплексний характер, період та частота цих коливань взаємопов'язані;

- можливість існування кількох сценаріїв розвитку соціально-економічної системи, тобто існування стійких та нестійких динамічних режимів за одних тих самих значень параметрів системи;

- виникнення субгармонічних коливань;

- існування стійких автоколивань $з$ обмеженою амплітудою;

- можливість взаємного впливу автоколивань системи і вимушених коливань, за якого можливе як посилення результуючих коливань, так і взаємне гасіння коливань;

- наявність ефректу синхронізації: за наявності навіть дуже слабких зв'язків між динамічними системами рух цих систем стає взаємопов'язаним, узгодженим, установлюється єдина (співмірна) частота коливань;

- взаємодія різних видів динамічних процесів у нелінійних системах: у зв'язку з відсутністю принципу суперпозиції в нелінійних системах взаємодія різних видів коливань може породжувати кілька стійких та нестійких режимів, можуть виникати полігармонічні коливання; взаємодія коливань може призвести до взаємного впливу різних динамічних процесів, до посилення або послаблення результуючого руху;

- біфуркація розв'язків за зміни параметрів системи та (або) зміни зовнішнього впливу: у процесі неперервної зміни одного або декількох параметрів системи або за наявності зовнішнього впливу система втрачає стійкість, що призводить до появи нових стійких або нестійких режимів, що залежить від набору параметрів системи. У точці біфуркації відбувається зміна сценарію розвитку системи, проявляється незворотність розвитку системи, неможливість абсолютного повернення системи в початковий стан за рахунок появи нових властивостей, що не існували раніше;

- можливість переходу до стійких станів: у процесі еволюції система може втратити стійкість, при цьому виникають нові стани, деякі з яких $€$ стійкими, система переходить до наступного стійкого стану і продовжує розвиватися в ньому до чергової втрати стійкості;

- можливість появи катастроф - стрибкоподібних змін, різких якісних змін, що виникають унаслідок реакції системи на плавну зміну параметрів або зовнішніх умов;
- існування в нелінійних моделях як розв'язків, що властиві лінійним моделям, так і складних стійких та нестійких режимів;

- можливість появи детермінованого хаосу хаотичного руху повністю детермінованої системи;

- можливість існування дивного аттрактора стійкого різноманіття нестійких траєкторій;

- самоорганізація нелінійних систем - процеси спонтанного впорядкування (переходу від хаосу до порядку), створення й еволюція структур у відкритих нелінійних середовищах.

Нелінійні системи є набагато складнішими, ніж лінійні системи, мають у своїй структурі різні стани, які відповідають різним допустимим законам розвитку цієї системи. Принципова відмінність нелінійних систем від лінійних полягає ще й у тому, що поведінка кожної підсистеми нелінійної системи на відміну від лінійної залежить від координації з іншими. Підсистеми лінійних систем слабо взаємодіють між собою і практично незалежно входять у систему. Важлива особливість нелінійних систем - можливість самоорганізації, тобто утворення $з$ фрізичного (біологічного, економічного, соціального) хаосу стійких упорядкованих структур з істотно новими властивостями систем.

Урахування нелінійності має величезне значення не лише для моделювання та прогнозування соціально-економічних систем. У контексті нелінійності необхідно досліджувати будь-які соціально-економічні процеси, розглядати методи управління економічною ефективністю, методи антикризового управління, приймати управлінські рішення на будь-якому рівні тощо.

Нелінійність є концептуальною ідеєю сучасною наукової парадигми, яка розкриває властивості систем, здатних до самоорганізації. Розглядаючи особливості френомену нелінійності [8, с. 50-51], науковці доходять висновку, що:

- завдяки нелінійності має силу найважливіший принцип «зростання малого» або «посилення фрлуктуацій»;

- певні класи нелінійних відкритих систем демонструють порогову чутливість: нижче порогу все зменшується, забувається, не залишає жодних слідів у природі, науці, культурі, а вище, навпаки, багаторазово зростає;

- нелінійність породжує так званий квантовий есрект - дискретність шляхів еволюції нелінійних систем, тобто в конкретному нелінійному середовищі можливий не будь-який шлях еволюції, а лише певний спектр цих шляхів;

- нелінійність визначає можливість неочікуваних (емерджентних), випадкових змін перебігу процесів.

Розуміння всіх зазначених ефектів нелінійності $€$ вкрай важливим під час дослідження та прогнозування соціально-економічних систем, які фрункціонують в умовах нестабільності, нестійкості, неви- 
значеності. На наше глибоке переконання, лише використання методів нелінійної динаміки дасть змогу побудувати адекватні моделі соціально-економічних систем та отримувати ґрунтовні висновки щодо розвитку цих систем.

Висновки 3 проведеного дослідження. Результати дослідження свідчать, що сучасні соціально-економічні системи фрункціонують в умовах нестабільності, постійних змін та криз. Ці об'єктивні умови потребують зміни парадигми моделювання та прогнозування соціально-економічних систем, переходу до нелінійної парадигми моделювання, до використання під час моделювання соціально-економічних систем методів нелінійної динаміки. Використання методів нелінійної динаміки дасть змогу спрогнозувати весь спектр можливих станів і варіантів майбутнього розвитку соціально-економічної системи, який є наслідком посилення нелінійності економічного середовища. Застосування методів нелінійної динаміки, розуміння особливостей феномену нелінійності під час дослідження соціально-економічних систем дають змогу не лише отримувати цілісну картину можливих шляхів розвитку соціально-економічної системи, прогнозувати перебіг економічних процесів, а й подолати можливі кризи 3 найменшими втратами та запропонувати заходи для досягнення сталого розвитку економіки.

\section{БІБЛІОГРАФІЧНИЙ СПИСОК:}

1. Малков С.Ю. Нелинейная динамика нелинейного мира. Сайт С.П. Курдюмова. URL: http://spkurdyumov.ru/economy/nelinejnaya-dinamikanelinejnogo-mira/ (дата звернення: 03.04.21).

2. Козлов Д.А. Методы нелинейной динамики в моделировании макроэкономических процессов. URL: https://ideas.repec.org/a/scn/031151/14527934. html (дата звернення: 29.03.2021).

3. Петров Л.Ф. Методы нелинейной динамики как инструменты управления экономической эфрфективностью. Эфрфективное антикризисное управление. 2011. № 2. С. 58-67.

4. Епифанова Н.Ш. Особенности и тенденции развития нелинейной экономической парадигмы. Экономика и менеджмент в условиях нелинейной динамики : монограсрия / под ред. д.э.н., профр. А.В. Бабкина. Санкт-Петербург : Политехн. ун-т, 2017. С. 9-49.

5. 5Данилов Ю.А. Нелинейность. Сайт С.П. Курдюмова. URL: http://spkurdyumov.ru/introduction/znakomstvo/ (дата звернення: 01.04.21).

6. Петров Л.Ф. Методы динамического анализа экономики : учебное пособие. Москва : ИНФРА-М, 2010. $239 \mathrm{c}$.

7. Петров Л.Ф. Проблемы построения моделей экономической динамики. Вестник РЭА. 2008. № 4. С. 88-92.

8. Князева Е.Н., Курдюмов С.П. Основания синергетики: Синергетическое мировидение. Москва : ЛИБРОКОМ, 2010. 256 с.
9. Синергетичні та еконофрізичні методи дослідження динамічних та структурних характеристик економічних систем : монографрія / В.Д. Дербенцев та ін. Черкаси : Брама-Україна, 2010. 287 с.

10. Занг В.-Б. Синергетическая экономика. Время и перемены в нелинейной экономической теории / пер. с англ. Н.В. Островской и др. Москва : Мир, 1999. 335 c.

11. Нелинейная динамика глобальных процессов в природе и обществе / под ред. И.В. Ильина, Д.И. Трубецкова, А.В. Иванова. Москва : Московскмй университет, 2014. 456 с.

12. Лебедев В.В., Лебедев К.В. Математическое моделирование нестационарных экономических процессов. Москва, 2011. 336 с.

13. Лисичкина Н.В., Голоктионова Ю.Г. Синергетика как способ решения проблемы прогнозирования динамики развития сложных социально-экономических систем. Фундаментальные исследования. 2015. № 7-2. С. 413-417.

14. Якімцов В.В. Теоретико-методологічні засади синергетичної ефрективності фрункціонування складних соціо-еколого-економічних систем : дис. ... докт. екон. наук : 08.00.06. Львів, 2019. 435 с.

15. Коломієць С.В. Зміна парадигми управління: нелінійний підхід. Науковий погляд: економіка та управління. 2020. № 2(68). С. 204-209.

\section{REFERENCES:}

1. Malkov S.Yu. Nelineynaya dinamika nelineynogo mira [Nonlinear dynamics of a nonlinear world] Sayt S.P. Kurdyumova: [Site of Kurdyumov Sergei]. Available at: http://spkurdyumov.ru/economy/nelinejnaya-dinamika-nelinejnogo-mira/ (accessed 03 April 2021).

2. Kozlov D.A. Metody nelineynoy dinamiki v modelirovanii makroekonomicheskikh protsessov [Methods of nonlinear dynamics in modeling macroeconomic processes]. Available at: http://spkurdyumov.ru/economy/nelinejnaya-dinamika-nelinejnogo-mira/ (accessed 29 March 2021)

3. Petrov L.F. (2011) Metody nelineynoy dinamiki kak instrumenty upravleniya ekonomicheskoy effektivnost'yu [Nonlinear dynamics methods as tools for managing economic efficiency]. Effective crisis management, vol. 2, pp. 58-67.

4. Epifanova N.Sh. (2017) Osobennosti i tendentsii razvitiya nelineynoy ekonomicheskoy paradigm [Features and development trends of a nonlinear economic paradigm]. Ekonomika i menedzhment $v$ usloviyakh nelineynoy dinamiki [Economics and Management in the Conditions of Nonlinear Dynamics]. SPb.: Izd-vo Politekhn. pp. 9-49.

5. Danilov Yu.A. Nelineynost [Non-linearity] Sayt S.P. Kurdyumova: [Site of Kurdyumov Sergei]. Available at: http://spkurdyumov.ru/introduction/znakomstvo/ (accessed 01 April 2021)

6. Petrov L.F. (2010) Metody dinamicheskogo analiza ekonomiki: ucheb. posobie [Methods of dynamic analysis of the economy : textbook ]. Moscow : INFRA-M. (in Russian)

7. Petrov L.F. (2008) Problemy postroeniya modeley ekonomicheskoy dinamiki [Problems of construct- 
ing models of economic dynamics]. Bulletin of the REA, vol. 4, pp. 88-92.

8. Petrov L.F. (2011) Metody nelineynoy dinamiki kak instrumenty upravleniya ekonomicheskoy effektivnost'yu [Nonlinear dynamics methods as tools for managing economic efficiency]. Effective crisis management, vol. 2, pp. 58-67.

9. Derbentsev V.D., Serdiuk O.A., Soloviov V.M., Sharapov O.D. (2010) Synerhetychni ta ekonofizychni metody doslidzhennia dynamichnykh ta strukturnykh kharakterystyk ekonomichnykh system [Synergetic and econophysical methods for studying the dynamic and structural characteristics of economic systems]. Cherkasy: Brama-Ukraina. (in Ukrainian)

10. Zang W.-B. (1999) Sinergeticheskaja jekonomika. Vremja i peremeny v nelinejnoj jekonomicheskoj teorii [Synergetic Economics: Time and Change in Nonlinear Economics]. Moscow: Mir. (in Russian)

11. Il'ina I.V. Trubetskova D.I., Ivanova A.V. (2014) Nelineynaya dinamika global'nykh protsessov $v$ prirode i obshchestve [Nonlinear dynamics of global processes in nature and society]. Moscow: University of Moscow. (in Russian)
12. Lebedev V.V., Lebedev K.V. (2011) Matematicheskoe modelirovanie nestatsionarnykh ekonomicheskikh protsessov [Mathematical modeling of non-stationary economic processes]. Moscow. (in Russian)

13. Lisichkina N.V., Goloktionova Yu.G. (2015) Sinergetika kak sposob resheniya problemy prognozirovaniya dinamiki razvitiya slozhnykh sotsial'no-ekonomicheskikh system [Synergetics as a way to solve the problem of forecasting the dynamics of the development of complex socio-economic systems]. Basic research, vol. 7-2, pp. 413-417.

14. Yakimtsov V.V. (2019) Teoretiko-metodologichni zasadi sinergetichnoï efektivnosti funktsionuvannya skladnikh sotsio-ekologo-ekonomichnikh system [Theoretical and methodological principles of synergetic efficiency of complex socio-ecological-economic systems] (Doctor of economic sciences Thesis), Lviv: Lviv National Agrarian University.

15. Kolomiiets S.V. (2020) Zmina paradigmi upravlinnya: neliniyniy pidkhid [Changing the management paradigm: a nonlinear approach]. Scientific view: economics and management, vol. 2 (68), pp. 204-209. 